\title{
Sociopragmatic Functions of Discourse Markers in International Law Texts
}

\author{
Davood Mashhadi Heidar \\ Department of English, Khorasgan (Isfahan) branch, Islamic Azad University, Isfahan, Iran \\ Email: davoodm_tarbiatmodares@yahoo.com \\ Reza Biria \\ Department of English, Khorasgan (Isfahan) branch, Islamic Azad University, Isfahan, Iran
}

\begin{abstract}
This paper is an attempt to clarify the status of discourse markers in International Law Texts. Discourse markers, also having been studied under various labels including discourse operators, pragmatic connectives, cue phrases, discourse connectives, and sentence connectives, are used extensively in both spoken and written language to signal the structure of the discourse. Research on this area has shown the importance of discourse markers in communication for marking discourse structure, but almost little attention has been paid to their importance in written language, especially in International Law Texts. This paper looks at the use of discourse markers in a corpus of International Law investigating what discourse markers signal, and when they tend to be used in International Law Texts. Therefore, a combination of qualitative and quantitative methods, which ranges from macro-investigation by Wordsmith (Scott 1996) to a micro- discourse analytic examination, is used in the study. The results indicate that discourse markers serve as useful maneuvers to structure and organize International Law Texts. In the end, the study also discusses some possible pedagogical implications involved in preparing ESP learners to become communicatively more competent in their field of study.
\end{abstract}

Index Terms - discourse markers, pragmatic connectives, discourse operators, international law texts

\section{INTRODUCTION}

Discourse markers are expressions such as those in italics in the following sentences:

a. John was late. So, I decided to leave without him.

b. I can't drive a car. And Kim can't either.

c. Jane can swim. But she can't ski.

d. He'll probably enjoy water skiing, even though he prefers to ski in the snow.

e. His voice was very weak, yet the students understood him.

f. Dr. Jones couldn't lecture for the entire hour, for he had a sore throat.

Discourse markers (henceforward, DMs), having been termed differently by different crowds of researchers inclusive of cue phrases (Knott and Dale, 1994), discourse connectives (Blakemore, 1987, 1992), discourse operators (Redeker, 1990, 1991), pragmatic connectives (Van Dijk, 1979; Stubbs, 1983), pragmatic markers (Fraser,1988, 1990; Schiffrin, 1987), sentence connectives (Halliday and Hasan, 1976), have been the subject of investigation in linguistics for the past ten years, with an abundance of articles publishing yearly.

DMs are a linguistic devise that speakers use to signal how the upcoming unit of speech or text relates to the current discourse state (Schiffrin, 1987) for instance, DMs can signal changes in discourse structure, as exemplified by 'by the way' to mark the start of a digression and 'any way' to mark the return from one. In human-human task oriented dialogues, DMs abound. Previous work shows the importance of DMs in dialogues, but very limited research has been undertaken on the range and diversity of DMs in International Law Texts. Drawing on the work of researchers working on DMs, this paper sets forth what DMs signal, and when they tend to be used in International Law Texts. This paper will first review past theoretical work on DMs to provide an idea of what main issues have been raised. Following this, by undertaking a corpus-based analysis of International Law Texts the research reviews definitions of DMs, by classifying them according to specific categorical framework. This study does not claim to offer detailed study of individual DMs; the main aim here is to offer a broader and wide-angled corpus-driven account of DMs in International Law Texts.

\section{REVIEW OF LITERATURE}

"The analysis of discourse markers is part of the more general analysis of discourse coherence-how speakers and hearers jointly integrate forms, meaning, and actions to make overall sense of what is said" (Schiffrin, 1987, p.49). Coherence relations, discourse relations, or rhetorical relations are different means to achieve coherence in discourse. Despite some similarities amongst rhetorical relations, discourse relations, and coherence relations, there is some 
dissimilarity amongst them, mainly in that rhetorical relations focus attention on the writer's intentions and the effect of the relation on the reader. An early reference to DMs as part of discourse coherence and a linguistic entity was made by Labov and Fanshel (1977). Levinson (1983), in his book named Pragmatics, viewed DMs as an independent class to be studied, although he did not entitle it. Within the past few years there has been an increasing interest in the status of DMs in the course of discourse, while focusing on what they are, what they mean, and what functions they fulfill. One of the most detailed efforts to study elements which mark "sequentially-dependent units of discourse" is made by Schiffrin (1987) who labels them "discourse markers". Schiffrin suggests that DMs do not easily fit into a linguistic class. In fact she goes so far as to suggest that paralinguistic features and nonverbal gestures are also DMs. Zwicky (1985) put into words an interest in discourse markers as a class when he stated that DMs must be separated from other function words, and that they routinely manifest themselves at the beginning of sentences, are prosodically autonomous, and are syntactically detached from the rest of the sentence in which they present themselves and construct no variety of unit with neighboring words. He also puts across that discourse markers all have pragmatic functions [e.g. the role relating the current utterance with a larger discourse] rather semantic ones [e.g. indicating sentence type]. Redeker (1991) puts down the notion of core meaning for DMs. There she calls DMs "discourse operators" putting forward that "the core meaning should specify the marker's intrinsic contribution to the semantic representation that will constrain the contextual interpretation of the utterance" (Redeker, 1991, p. 1164). She defines a discourse operator as a word or phrase that is uttered with the primary function of bringing to the listener's attention a particular kind of linkage of the upcoming utterance with the immediate discourse context. An utterance in this definition is an intentionally and structurally bounded, usually clausal unit (Redeker, 1991). Being the owner of the same attitude as Sanders et al. (1992), taking down that a coherence relation is an aspect of meaning of two or more discourse sentences that cannot be described in terms of the meaning of the sentences in isolation, she puts forward the following model of discourse coherence. Two discourse unites are related:

(a) Ideationally, if their utterance in the given context entails the speaker's commitment to the existence of that relation in the world the discourse describes. For example, temporal sequence, elaboration, cause, reason, and consequence (Redeker,1991, p. 1168);

(b) Rhetorically, if the strongest relation is not between the propositions expressed in the two units but between the illocutionary intentions they convey. For example, antithesis, concession, evidence, justification, and conclusion (Redeker, 1991, p. 1168);

(c) Sequentially, if there is a paratactic relation (transition between issues or topics) or hypotactic relation (those leading into or out of a commentary, correction, paraphrase, aside, digression, or interruption sentence) between only loosely related (or indirectly related adjacent discourse sentences (Redeker, 1991, p. 1168). "When two adjacent discourse unites do not have any obvious ideational or rhetorical relation....their relation is called sequential" (Redeker, 1990, p. 369).

Blakemore (1987, 1992) considers DMs as a type of conventional implicature, bringing into focal point how "discourse connectives" (she calls them) impose constraints on implicatures. Blakemore $(1987 ; 1992)$ submits that DMs do not have a representational meaning the way lexical expressions do, but have a procedural meaning, incorporating instructions about how to manipulate the conceptual representation of the utterance. Despite of different perspectives taken by different crowds of researchers, DMs impose a relationship between some aspects of the discourse they are part of. In other words, they serve as a linkage between the upcoming discourse and the current discourse with the aim of backing the interlocutors to interconnect the illocutionary intentions they convey.

The first stumbling block in probing these markers signaling coherence relations has to do with an exact definition of these markers. In the company of words we may be confronted with: discourse markers, discourse operators, discourse connectives, lexical markers, pragmatic connectives, cue phrases, and a bunch of other terms coined and used by different researchers. The definitions are also equally as miscellaneous as the terms used. Fraser (1999) puts forward that DMs are conjunctions, adverbs and prepositional phrases that connect two sentences or clauses together. Redeker $(1990 ; 1991)$ proposes that DMs link not only contiguous sentences, but also the current sentence or utterance with its immediate context. Schiffrin $(1987 ; 2001)$ has an idea that DMs can have both local and global functions. She also takes items such as oh, y'know, I mean as DMs. To Blakemore (1987; 1992; and 2002), working within the scheme of Relevance Theory (Sperber and Wilson, 1986), DMs impose constraints on the implicatures the hearer can extract from the discourse; that is, discourse without DMs is open to more than one type of implicature. Louwerse and Mitchell (2003) view DMs as cohesive devices that gesture coherence relations, pointing transition points in a sentence, between sentences, at the both local and global levels of discourse. Halliday and Hasan (1976) also see DMs as cohesive devices.

Different incentives have persuaded the study of DMS. By way of illustration, Sanders et al. (1992) were engrossed by the adequacy of taxonomy and by the psychological plausibility of coherence relations. Another aim of enquiries of DMs has been to come up with the most appropriate markers in a text system. Grote et al. (1997) concentrated on the possible ways to mark the Concession relation in both English and German. To achieve these goals, different procedures there are to move towards an investigation of DMs. One technique is to develop taxonomy of DMs, and then observe what sort of relations they signal. This is the approach taken by Knot et al. (Knot, 1996; Knot and Dale, 1994; and Knot and sanders, 1998). Like others, this study is mainly concerned with the status of DMs, investigating what DMs are, and what functions they fulfill in International Law Texts. The present paper yields a characterization of 
particular types of signaling the coherence relations that DMs provide. The paper strives for an answer to the question about coherence in International Law Texts: what kind of signaling is available to readers to process in International Law Texts?

The plurality of language bordering DMs casts back different research interests, as well as stumbling blocks in handling them sufficiently in theoretical terms. In the majority of the researches undertaken during the past few years, inclusive of this one, DMs are defined as linguistic units which satisfy to a great extend a non-propositional and connective function in the course of discourse. They gesture moves in the changing process of discourse, index the relation of an upcoming piece of discourse to the already-existing context and help the reader/speaker with the integration of forms, meaning, and actions (Schiffrin, 1987) in order to perceive the coherence within the text and figure out what the speaker or writer is trying to convey.

\section{A Framework for Discourse Markers}

With regard to DMs, using data from International Law corpus (see the Method section for details of the data), the aim of the present study is to put forward a wide-angled account of DMs in International Law Texts and to investigate what roles they have to play and what functions they have to fulfill.

The following criteria are used for a linguistic item to be identified as a DM.

\section{Position}

Most DMs happen to take initial position. Initiality brings to light loads of functions designated by DMs, such as then in (a) signaling sequence, and thus in (b) signaling consequence.

(a) Then the mode by which the parties claim to have established sovereignty over the territory will gain new relevance. (INTERNATIONAL LAW)

(b) Thus, the possibility of the disputes over jurisdiction is minimized. (INTERNATIONAL LAW)

The position occupied by some DMs is bendable. DMs can also be slotted in sentence-medial position for an attention-holding purpose or to shed light on meaning, such as however in (a) and thus in (b).

(a) Such observers remain, however, under the jurisdiction of their sending state rather than that of the "host" state. (INTERNATIONAL LAW)

(b) The Agreement has thus been of minimal significance. (INTERNATIONAL LAW)

\section{Multigrammaticality}

Grammatically point of view, DMs are distinct. DMs are diverse in terms of their categorical heterogeneity (Bazzanella and Morra, 2000). They do not make up a sole, clearly-defined grammatical class, rather are taken from various grammatical and lexical catalogues. By way of illustration, yet, nor, for, and so, etc. are coordinating conjunctions; however, moreover, still, etc. are conjunctive adverbs; as soon as, although, until, etc. are subordinating conjunctions; by way of illustration, in the end, by the way, etc. are prepositional phrases; certainly, absolutely, surely, etc. are adverbs; this is the point, in other words, and other expressions like those are meta-expressions. Not all the above-mentioned linguistic items can be viewed as DMs. The function fulfilled by DMs is context-oriented; that is, the status of a DM is contextually referenced. For instance, so can signal summarizing, or pinpointing consequences pending the context in which it is used.

\section{Indexicality}

DMs play the role of indexical expressions gesticulating the linkage between forthcoming pieces of discourse and the current discourse; that is, they assign the discourse unites a logical link. DMs are either conceptless, e.g. oh, well, etc.; partially conceptual, e.g. so-meaning 'cause'; and conceptually rich such as thirdly, honestly, I suppose. As Aijmer (2002) states lexical words used as DMs have had a shift of function from propositional meaning to textual function through a process of grammaticalization.

\section{Optionality}

Optionality is another decisive factor in identifying DMs. They are both grammatically and semantically optional; this means, their being used has nothing to do with the truth value of the propositions. They even can be left out without syntactic impairment or semantic change. But readers or listeners lack sufficient hints as a result of which they cannot best figure out the relations among discourse pieces. Take the following example in which the presence or absence of all the DMs in bold can affect the signaling of the writer or speaker's attitude.

If accretion occurs on a boundary river (i.e. between two states) then the international boundary changes, whereas with cases of avulsion the international boundary will remain where it was originally established. (INTERNATIONAL LAW)

None of the above parameters in isolation will suffice to serve as a cornerstone based on which to decide whether or not a linguistic item is a DM. Instead, a combination of criteria needs to be taken into account. Calling attention to the descriptive worth for International Law discourse of recurring patterns and of frequency distribution, the study at hand implements a corpus-driven approach laying emphasis on the level of textual coherence. Thus, DMs are considered to be of pragmatic importance. The theoretical framework adopted here holds in arms a function-oriented account and is built upon Schiffrin's (1987) notion of multi-dimensional model of coherence. Keeping in line with Maschler (1994, 1998) DMs can be classified in accordance with the following functional headings, while taking into account that any case in point is capable of performing more than one function (Lenk, 1998; Anderson, 2001).

Referential category 
Working on a textual level, DMs signal relationships between former and subsequent activities in the course of discourse. An assortment of relationships are specified by conjunctions, for instance both, and designate coordination, therefore, consequently designate result (cause), still, on the contrary indicate contrast, anyway indicates digression, and or indicates disjunction.

\section{Structural category}

DMs in this class mark links and transitions between topics. As an instance DMs like now, well, ok signal launching or sealing of topics, while second, thirdly, next, are used to indicate sequence, and now, so, how about, are to signal topic shifts. DMs demonstrate the discourse in progress. Interactionally point of view, DMs can affect the turn-taking distribution. At this level, DMs can also display the continuation of the topic at hand (so, yeah), they can also serve as a device to summarize ideas, etc.

\section{Cognitive category}

At textual level, DMs are informants of the writers' cognitive state. Coherence and unity of the text may collapse if the writer does not have signaled topic shifts. Cognitive DMs guide the reader to create a mental image of the progressing discourse. DMs such as I see, I think, denote the thinking process and DMs such as I mean, that is, show the writer's intention to reformulate, like, I mean, signal the writer's willingness to elaborate, etc.

\section{METHOD}

A corpus of Law text from International Law (Wallace, 1986) was used in the present study. The International Law corpus includes data adding up to10914 words, extracted from the book entitled "International Law" written by Rebecca M.M. Wallace (1986).

\section{A. Data Selection}

The present study was an attempt to deal with the issue of DMs in International Law Texts with the aim of providing a wide-angled account of what roles DMs have to play, and what functions they have to fulfill in International Law Texts. As a result, data from International Law was used as the basis for analysis. Such data can illuminate how far DMs go to contribute to the coherence and unity of International Law Texts. The analysis of such data gives ESP (English for Specific Purposes) learners working in the field of International Law the capability to pragmatically incorporate DMs in their both writings and discussions. In this respect, the study may be of particular value to ESP teachers, in particular those teaching International Law to EFL or ESL learners, while conveying broader pedagogic significance for the communicative teaching of International Law to these learners.

\section{B. Design}

As DMs manoeuvre inside and outside a clause, what is needed is an analysis which encompasses moves from lexical or sentential levels to discoursal ones. As a result, a combination of qualitative and quantitative methods ranging from a macro-investigation by Wordsmith tools (Scott, 1996) to a micro-discourse analysis is used in the study. To start the investigation, 28 lexical items being distinguished as DMs were selected. Then, the linguistic items were further studied by scrutinizing the text qualitatively in order to come up with regularities and frequent patterns in the data. A frequency list was also run for the 28 linguistic items to see how frequent each DM is in International Law Texts.

\section{RESULTS}

This section deals with the functional paradigm of DMs in International Law Texts in accordance with Schiffrin's (1987) multi-functional model of coherence.

\section{A. Referential}

In written language, on the referential level, conjunctions are repeatedly used to mark the link between the-alreadythere discourse units and the upcoming ones. They actually provide indexical direction to different semantic relations. DMs at this level provide information about the ways in which units of discourse are sequenced, and how they are coordinated. They also indicate causal (because), contrastive (whilst, however, but), consequential (consequently), and disjunctive (or) relations. As exemplified discoursal links can be demonstrated using this type of referential marker.

\section{Indicating causal relationship}

DMs are useful in indicating causal relations. Words such as, because, since can be used in discourse to signal this type of relationship. As illustrated below, in the corpus driven from International Law Texts, the word, because (line 2 and 4) has been used to communicate this type of discoursal link.

$<1>$ The fifth freedom which is the right to carry traffic between the grantor state and another state's territory has, because it is more extensive, not been so readily granted. (INTERNATIONAL LAW)

<2> "Lord Haw Haw" was found guilty of treason because of his pro-Nazi propaganda radio broadcasts from Germany to Britain during the war. (INTERNATIONAL LAW)

\section{Indicating consequences}


DMs are repeatedly used to convey consequential links amongst discoursal units. DMs such as 'as a result' and 'so' can indicate consequences in discourse. As shown below in International Law Texts words like therefore (line 2), thus (line 5) and consequently (line 6) have been drawn upon to signal consequences or results.

$<1>$ The display of sovereignty required to establish title by occupation, for example, over territory inhospitable to habitation may, therefore, be minimal and in certain circumstances may be little more than symbolic. (INTERNATIONAL LAW)

<2> ...granting of independence to former colonial possession, involves the replacement of one sovereign by another and thus a derivative title to territory. (INTERNATIONAL LAW)

$<3>$ Consequently, a number of states adopted a modified absolute immunity policy. (INTERNATIONAL LAW)

\section{Indicating contrasts}

On the referential level DMs are recurrently drawn upon to signpost the relationship of an existing utterance with the preceding one. DMs such as but (line 3), although (line 4), however (line 6), though (line 7), yet (line 9), whilst (line 12), while (line 15), albeit (line 17) and and (line 19) are frequently used in International Law Texts to designate contrastive relationships amongst units of discourse.

$<1>$ It shows that in the case of such territories the acquisition of sovereignty was not generally considered as effected unilaterally through 'occupation' of terra nullius by original life title but through agreements concluded with local rulers...(INTERNATIONAL LAW)

<2> Although continuous in principle, sovereignty cannot be exercised in fact at every moment on every point of a territory. (INTERNATIONAL LAW)

<3> The United States, however, does continue to refuse recognition of the incorporation of Estonia, Latvia and Lithuania into the Soviet Union, though the Baltic States were conquered before World War II. (INTERNATIONAL LAW)

<4> The Convention, which is not yet in force, is based essentially on the 1961 Vienna Convention on Diplomatic Relations. (INTERNATIONAL LAW)

<5> The state from which the gun was fired has jurisdiction under the subjective territorial principle, whilst the state where the injury was sustained has jurisdiction under the objective territorial principle. (INTERNATIONAL LAW)

$<6>$ The right to carry traffic from the territory of the state granted the right to the grantor state is guaranteed by the third freedom, while the fourth freedom is the right to carry traffic from the grantor state's territory to the territory of the state granted the right. (INTERNATIONAL LAW)

$<7>$ His duty of allegiance was founded on his having acquired a British passport, albeit fraudulently. (INTERNATIONAL LAW)

$<8>$ Discovery, per se, does not establish a good title, giving only an inchoate and not a definite title of sovereignty. (INTERNATIONAL LAW)

\section{Indicating Comparison}

Another function that DMs are exploited to signal is to indicate comparison. In the International Law corpus used in this study likewise (line 1) functions as a DM to designate comparison.

$<1>$ Non-national service staffs likewise enjoy immunity only in respect of their official acts. (INTERNATIONAL LAW)

\section{Indicating Disjunction and coordination}

Or and and are two DMs frequently used in the corpus to show discoursal relations in International Law Texts. Or (lines 2, 4 and 5) was repeatedly drawn upon to signal disjunction and possibility and and (line 8) was also commonly used to designate coordination.

$<1>$ The intermittence and discontinuity compatible with the maintenance of the right necessarily differ according as inhabited or uninhabited regions are involved, or regions enclosed within territories in which sovereignty is incontestably displayed or again regions accessible from, for instance, the high seas. (INTERNATIONAL LAW)

$<2>$ Discovery must be reinforced by an intention (animus) or will to act as sovereign. (INTERNATIONAL LAW)

<3>A state's territorial sovereignty extends over the designated land-mass, sub-soil, the water enclosed therein, the land under that water, the sea coast to a certain limit and the airspace over the land-mass and territorial sea. (INTERNATIONAL LAW)

\section{B. Structural}

In this category DMs such as right, alright, let me conclude the discussion are to signal opening and closing of topics, others like previously, before, finally inform the reader of how units of discourse are sequenced. So, now, and well can be used to signal topic shifts. Other DMs are exploited to signal continuation of topics and summarizing topics.

\section{Sequencing}

In the corpus under study previously (line1), today (line 1), before (line 3), then (line 4), finally (line 6), third (line 8), first (line 9) and second (line 12) have been used to signpost how successive units of discourse are sequenced. These DMs help the reader to figure out the logical sequence amongst segments of discourse in International Law Texts.

<1> Previously, force could legitimately be used. Today, diplomatic protests would have to be expressed... (INTERNATIONAL LAW)

<2> As to the length of time required before prescription will give good title... (INTERNATIONAL LAW) 
$<3>$ If accretion occurs on a boundary river (i.e. between two states) then the international boundary changes... (INTERNATIONAL LAW)

$<4>$... and title may finally only be established when an "acknowledgement of the facts" stance is adopted. (INTERNATIONAL LAW)

<5> The third, an action programme for 1982-86, was adopted late in 1981. (INTERNATIONAL LAW)

<6> The first four principles, territorial principle, nationality principle, protective (or security) principle and universality principle, were accepted by Harvard Research Draft Convention of 1935. (INTERNATIONAL LAW)

$<7>$ The second principal exception to territorial jurisdiction is diplomatic immunity.... (INTERNATIONAL LAW) Closing and opening of topics

DMs can mark the opening and closing of different discourse units. In the corpus of International Law Text used in this study as has been said (line 1) was drawn upon in the conclusion section to sum up and close the topic.

$<1>$ As has been said, states enjoy territorial sovereignty. (INTERNATIONAL LAW)

\section{Cognitive}

DMs on this level can reflect the interlocutor or writer's thinking processes. Well, for example signals delaying tactic to show the thinking process when an answer is not at hand (Svartvik, 1980, p. 171). DMs like that is and in other words while indicating a kind of reformulation can also be used to mark the writer's modification or clarification of the notions and concepts mentioned earlier. On the textual level, Muller (2005) observes like as a way to come up with an explanation, to introduce an exemplifier or to look for the right expression. I mean, as a DM, can be used to elaborate and clarify the propositional meaning in order to shed light on the intentions of the writer or to add to the meanings. Schiffrin (1987) claims that I mean can also be used to modify the writer's own opinions.

\section{Reformulation}

In the corpus under study DMs such as that is (line 2) and in other words (line 4) were used to mark the writer's intention to modify or clarify the notions and concepts mentioned earlier.

In fact the writer is to reformulate what he or she has put down earlier.

$<1>$ The means whereby title to territory may be established is essentially of academic interest-until, that is, a dispute arises and competing claims have to be to be assessed. (INTERNATIONAL LAW)

$<2>$ The right of the state in which the crime was initiated is, in other words, not restricted from exercising jurisdiction. (INTERNATIONAL LAW)

To recapitulate, the analysis undertaken so far suggests that DMs can come to fulfill a large variety of discourse functions in the three multi-categorical categories as topic switchers, coordinators, sequencers, comparison indicators, etc. We are fully aware of the fact that a narrow corpus-based study offers only little scope for in-depth analyses of individual DMs; however, it is hoped that the study undertaken here may highlight the main functional paradigm that this range of DMs have in International Law Texts, which in turn can contribute to a range of possibilities for sociopragmatic instruction of DMs in ESP classes (see 'pedagogical implications' below).

The second part of the result section comes up with the frequency of the DMs used in the International Law Corpus. The list of 28 DMs and the data are presented in Table 1. 
TABLE 1:

FREQUENCY OF DISCOURSE MARKERS IN THE INTERNATIONAL LAW CORPUS (10914 WORDS)

\begin{tabular}{|l|l|l|}
\hline Discourse markers & Frequency & International Law (\%) \\
\hline And & 156 & 1.42 \\
\hline Or & 66 & .60 \\
\hline But & 27 & .24 \\
\hline Although & 17 & .15 \\
\hline However & 15 & .13 \\
\hline Before & 12 & .10 \\
\hline Second & 9 & .08 \\
\hline While & 8 & .07 \\
\hline Even though & 7 & .06 \\
\hline Thus & 7 & .06 \\
\hline Consequently & 6 & .05 \\
\hline Though & 5 & .04 \\
\hline Nevertheless & 5 & .04 \\
\hline Yet & 5 & .04 \\
\hline Today & 5 & .04 \\
\hline Then & 4 & .03 \\
\hline Therefore & 4 & .03 \\
\hline Previously & 3 & .02 \\
\hline Because & 3 & .02 \\
\hline Whilst & 3 & .02 \\
\hline Albeit & 2 & .01 \\
\hline That is & 2 & .01 \\
\hline So & 2 & .01 \\
\hline Third & 2 & .01 \\
\hline In other words & 2 & .01 \\
\hline As has been said & 1 & .009 \\
\hline Finally & 1 & .009 \\
\hline Likewise & 1 & .009 \\
\hline & & \\
\hline
\end{tabular}

DMs drawn upon in the International Law Corpus tend to take place with a particularly heavy occurrence of referential and structural markers. As the Frequency Table indicates the range of DMs used is limited in and confined to a more frequent use of and, or, but, although, however, before and much less frequent use of likewise, finally, whilst, as has been said, third, so, that is, etc. Due to the limits of present computer software in differentiating the discoursal role of individual words, the words cited here may have other grammatical functions than those of DMs so making their classification sometimes difficult.

\section{PEDAGOGICAL IMPLICATIONS}

The range and the frequency of DMs used in the corpus reflect the nature of the linguistic input ESP learners in International Law are supposed to be exposed to and the pedagogic focus should be geared towards both the literal or propositional (semantic) meanings of words and their pragmatic use in International Law Texts. Many coursebooks locally-produced for ESP learners in International Law claim to focus on usage while they primarily focus on propositional content rather than on discoursal use. For example, words such as while, because, previously, consequently, etc are frequently emphasized in ESP classroom, whereas their pragmatic usages in International Law Texts to indicate the author's intention to draw a contrast, to show a causal relation, to sequence ideas, to signal results and consequences, etc are rarely focused upon. It is likely that the low propositional meanings of DMs have devalued their pedagogic significance, and hence contributed to their low status. It is only the propositional meanings of DMs that have been frequently attended to in the classroom. A general neglect of knowledge of DMs in the foreign language teaching curriculum seems to be a pedagogic reality (Romero Trillo 2002; Muller 2005). DMs which represent an aspect of pragmatic competence that forms the basis of one's ability to use language in culturally, socially, and situationally appropriate ways are useful devices not only for interpersonal and cross-cultural interaction but also for maintaining discourse cohesiveness and communicative effectiveness (Wierzbicka 1991). This study suggests a need to strengthen learners' pragmatic competence in International Law by creating space to improve their knowledge and use of DMs. Incorporation of DMs into ESP curriculum is necessary to help ESP learners enhance their communicative skills in their field of study and avoid misunderstanding in communication and this might provide learners with a sense of security in ESP courses.

\section{CONCLUSION}

Drawing data from the International Law corpus, the present study suggests a core functional paradigm of DMs and considers different uses of DMs in International Law Texts, using both qualitative and quantitative methods. Although the small corpus of the International Law data does not allow us to draw any strong conclusions, we hope to have shed light on the research potential of this underexplored area. The listed items in the Frequency Table are observations of 
frequently-occurring DMs in the International Law data and should not be considered as a comprehensive list of all the DMs in International Law. Since the study of DMs is still in its infancy, it is also premature to set up a full taxonomy of markers until there is greater agreement about the function of individual items, their meaning, their relevance for pedagogic contexts, and the actual number to be calculated as a genuine category. DMs mould a part of the basic composition of text in International Law and are informative contextual coordinates to construct and organize International Law Texts in referential, structural, and cognitive categories. On the referential level, DMs specify textual relationships foregoing and following the DM. These textual relationships comprise cause, contrast, coordination, disjunction, consequence, digression, comparison, etc. Structurally point of view, DMs are drawn upon to organize the discourse in progress and gesture links and transitions between topics, such as indicating sequence, topic shifts and summarizing opinions. Cognitively, they help in denoting the speaker's thinking processes, marking repairs such as reformulation, and elaboration. The results accord with evidence from a growing literature in pragmatics that they contribute to the management and development of discourse and perform important textual functions. Quantitatively, there is a considerable discrepancy between the use of DMs in different categories. Referential and structural markers such as and, however, although, or, and but tend to occur more frequently than cognitive markers like that is, in other words, and as has been said. Many common DMs used in the International Law Corpus are far less frequent: likewise, finally, in other words, third, albeit, etc. Within the kinds of DMs used in the International Law, there is a widespread use of referential and structural markers (and, but, because), but a very restricted use of markers to mark cognitive processes of the writer. Our analysis not only furthers knowledge of DMs; it also, we hope, has implications for teaching and learning, since inappropriate use of DMs can lead to misunderstandings, difficulties in coherent interpretation, and impediments to textual relations.

\section{REFERENCES}

[1] Aijmer, K. (2002). English Discourse Particles. Evidence from a Corpus. Amsterdam and Philadelphia: John Benjamins.

[2] Andersen, G. (2001). Pragmatic Markers and Sociolinguistic Variations. Amsterdam and Philadelphia: John Benjamins.

[3] Bazzanella, C. and L. Morra. (2000). Discourse markers and the indeterminacy of translation in I. Korzen and C. Marello (ed): On Linguistic Aspects of Translation. Alessandria: Edizioni dell' Orso.

[4] Blakemore, D. (1987). Semantic Constraints on Relevance. Oxford: Blackwell.

[5] Blakemore, D. (1992). Understanding Utterances: An Introduction to Pragmatics. Oxford and Cambridge: Blackwell.

[6] Blakemore, D. (2002). Relevance and Linguistic Meaning: The Semantics and Pragmatics of Discourse Markers. Cambridge University Press: Cambridge.

[7] Fraser, B. (1988). Types of English Discourse Markers. Acta Linguistica Hungarica, 38, 19-33.

[8] Fraser, B. (1990). An approach to discourse markers. Journal of Pragmatics, 14, 383-95.

[9] Fraser, B. (1999). What are discourse markers? Journal of Pragmatics, 31(7), 931-52.

[10] Grote, B., Lenke, N. and Stede, M. (1997). Ma(r)king concessions in English and German. Discourse Processes, $24,87-117$.

[11] Halliday, M. A. K. and Hasan. R. (1976). Cohesion in English. London: Longman.

[12] Knott, A. and Dale, R. (1994). Using linguistic phenomena to motivate a set of coherence relations. Discourse Processes 18 (1), 35-62.

[13] Knott, A. (1996). A Data-Driven Methodology for Motivating a Set of Coherence Relations. Unpublished Ph.D. dissertation, University of Edinburgh, Edinburgh, UK.

[14] Knott, A. and Sanders, T. (1998). The classification of coherence relations and their linguistic markers: An exploration of two languages. Journal of Pragmatics, 30, 135-175.

[15] Labov, W. and D. Fanshel. (1977). Therapeutic discourse. New York: Academic Press.

[16] Lenk, U. (1998). Discourse markers and global coherence in conversation. Journal of Pragmatics, 30(2), $245-57$.

[17] Levinson, S. C. (1983). Pragmatics. Cambridge: Cambridge University Press.

[18] Louwerse, Max M., and Heather M. H. (2003). Toward a taxonomy of a set of discourse markers in dialogue: A theoretical and computational linguistic account. Discourse Processes, 35 (3), 243-281.

[19] Maschler, Y. (1994). Metalanguaging and discourse markers in bilingual conversation. Language in Society, $23,325-66$.

[20] Maschler, Y. (1998). Rotse' lishmoa ke'ta? 'Wanna hear something weird/funny? [lit. 'a segment']: Segmenting Israeli Hebrew talk-in-action' in A. H. Jucker and Y. Ziv (ed): Discourse Markers: Descriptions and Theory. Amsterdam: John Benjamins.

[21] Muller, S. (2005). Discourse Markers in Native and Non-native English Discourse. Pragmatics \& Beyond New Series 138. Amsterdam and Philadelphia: John Benjamins.

[22] Redeker, G. (1990). Ideational and pragmatic markers of discourse structure. Journal of Pragmatics, 14, 367-381.

[23] Redeker, G. (1991). Review article: Linguistic markers of linguistic structure. Linguistics, 29 (6), 1139-72.

[24] Redeker, G. (1991). Linguistic markers of discourse structure. Linguistics, 29, 1139-72.

[25] Romero Trillo, J. (2002). The pragmatic fossilization of discourse markers in non-native speakers of English. Journal of Pragmatics, 34, 769-84.

[26] Sanders, T. Spooren, W. and Noordman, L. (1992). Toward a taxonomy of coherence relations. Discourse Processes, 15, 1-35.

[27] Schiffrin, D. (1987). Discourse Markers. Cambridge: Cambridge University Press.

[28] Schiffrin, D. (2001). Discourse markers: Language, meaning and context. In: Schiffrin, D., Tannen, D. \& Hamilton, H. E. (Eds.), The Handbook of Discourse Analysis, Blackwell, Malden, MA, 54-75.

[29] Scott, M. (1996). Wordsmith Tools. Oxford: Oxford University Press.

[30] Sperber, D. and Wilson, D. (1995). Relevance: Communication and Cognition, 2nd ed. Oxford: Blackwell.

[31] Stubbs, M. (1983). Discourse analysis. Chicago, IL: The University of Chicago Press. 
[32] Svartvik, J. (1980). 'Well in conversation' in S. Greenbaum, G. Leech, and J. Svartvik. (ed): Studies in English Linguistics: For Randolph Quirk. London and New York: Longman.

[33] Van Dijk, T. A. (1979). Pragmatic connectives. Journal of Pragmatics, 3, 447-456.

[34] Wierzbicka, A. (1991). Cross-cultural Pragmatics. The Semantics of Human Interaction. Berlin: Mouton de Gruyter.

[35] Zwicky, A. (1985). Clitics and particles. Language, 61, 283-305.

Davood Mashhadi Heidar is currently a PhD candidate in Teaching English as a Foreign Language in Islamic Azad University, Khorasgan Branch. His areas of interest include Discourse analysis, Critical discourse analysis, and ESP.

Reza Biria currently works as an Assistant Professor at Khorasgan Azad University, Isfahan. His research interests include teaching English as a second and foreign language and ESP. 